\title{
O USO DAS TIC NO AMBIENTE ESCOLAR PELOS PROFESSORES DE ENSINO TÉCNICO
}

\author{
Ana Cristina Cardoso Coimbra ${ }^{1}$, Fabiana Helena Zen Gorayeb ${ }^{1}$ \\ ${ }^{1}$ Pós graduada em Formação Pedagógica para educação profissional de nível médio, pelo CPS - Centro Paula Souza. E- \\ mail: anacriscoimbra@gmail.com \\ ${ }^{2}$ Pós - Graduada em Gestão de Marketing pela FAAP e Pós - Graduada em Docência para o Ensino Superior pela UNAR. \\ Docente do Centro Paula Souza. Prêmio de Professor Inovador: Primeiro lugar na categoria Sustentabilidade, Parceria \\ Inova Paula Souza/FEl. Sócia proprietária da Agência de Publicidade A5.
}

\section{RESUMO}

O presente artigo traz uma reflexão sobre como a utilização das Tecnologias da Informação e Comunicação (TIC), influenciaram em uma mudança significativa na escola contemporânea, e como os professores estão lidando com a quebra de paradigma de ter a tecnologia como aliada em suas aulas. É apresentado, por meio de entrevistas diretas, a opinião de dois professores sobre: como eles veem a utilização da tecnologia nas aulas, como as capacitações podem contribuir para a utilização das ferramentas de TIC em sala e como a infraestrutura disponibilizada nas escolas influenciam no uso da tecnologia junto aos alunos. A partir da análise do questionário ficou claro que os professores possuem predisposição para aprender novas tecnologias, que as capacitações são fundamentais para se manter atualizados e que uma boa infraestrutura é fundamental para a utilização das TIC em sala.

Palavras-chave: Tecnologia da Informação e Comunicação. Processo de ensino e aprendizagem. Capacitação.

\section{THE USE OF ICT IN THE SCHOOL ENVIRONMENT BY TECHNICAL EDUCATION TEACHERS}

\begin{abstract}
This paper brings a reflection on how the use of Information and Communication Technologies (ICT), influenced a significant change in contemporary school, and how teachers are dealing with the paradigm break of having technology as an ally in their classes. It is presented, through direct interviews, the opinion of two teachers on: how they see the use of technology in the classroom, how the training can contribute to the use of ICT tools in the classroom and how the infrastructure available in schools influence the use of technology with students. From the analysis of the questionnaire it was clear that teachers are predisposed to learn new technologies, that trainings are a fundamental tool to keep up to date and that a good infrastructure is fundamental for the use of ICT in the classroom.

Keywords: Information and Communications Technologies. Teaching and learning process. Training.
\end{abstract}

\section{INTRODUÇÃO}

Vivemos em uma época em que ocorrem grandes avanços tecnológicos. Inovações surgem a todo momento, trazendo em sua esteira novos desafios a serem vencidos, novas formas de trabalho, de estudo e de convivência. Isso é mais percebido no que concerne as Tecnologias da Informação e Comunicação (TIC). As TIC, segundo Pacievitch (2018), podem ser definidas como um conjunto de recursos tecnológicos, utilizados de forma integrada, com um objetivo comum. Elas têm provocado grandes transformações na vida das pessoas, impactando em aspectos sociais, políticos, econômicos, culturais e educacionais, como no exercício da atividade de docência.

Ignorar esta realidade pode não ser um bom caminho. Embora toda mudança exija adaptações e por consequência a superação de desafios, não podemos deixar de reconhecer que neste ponto, o uso de novas tecnologias se traduz em uma grande oportunidade a ser explorada pelas escolas e professores.

Quando tratamos de desafios, queremos dizer que a aplicação dos recursos tecnológicos 
na atividade docente exige a quebra de paradigmas, desapego dos tradicionais métodos de ensino, necessidade de capacitação e atualização dos docentes, além de concentração de esforços para criar, reorganizar e sistematizar o novo modelo de ensino-aprendizagem.

Como oportunidade, através das novas tecnologias, torna-se possível construir e difundir conhecimentos de uma maneira mais dinâmica, com grandes possibilidades de acesso à informação e de abordagem dos conteúdos, abdicando-se de tarefas repetitivas centrando o foco nos aspectos mais relevantes da aprendizagem.

O presente artigo foi desenvolvido com o objetivo de demonstrar a importância das novas tecnologias como ferramentas de auxílio no processo de ensino e aprendizagem e como elas podem contribuir para elevação do nível da qualidade da atividade docente, as principais dificuldades que são enfrentadas na adoção destes recursos e como os professores devem se preparar para atuar e explorar adequadamente suas potencialidades, já que o uso da tecnologia por si só não se traduz em um processo de ensino eficaz.

O contexto comumente conhecido sobre 'tecnologia' foi desenvolvido socialmente, culturalmente e economicamente. Nosso intuito é demonstrar que a tecnologia não se reduz a objetos, como: computadores, retroprojetores, aparelhos celulares, internet, cabos, redes, tablet's, iphones e ipads. A tecnologia vai além. Ao tentarmos encontrar o significado do termo tecnologia, localizamos diversos sentidos e traduções. Segundo Rodrigues (2001), a palavra tecnologia é a junção do termo tecno (saberfazer) e logia (razão). Portanto, tecnologia significa a razão do saber fazer. Nós seres humanos unimos técnica e conhecimento para criar e recriar novas tecnologias e que se tornam fruto da História da evolução da humanidade.

Porém esse saber-fazer tecnológico é aplicado em diversos setores como: sociais, ambientais, mercadológicos, educacionais. O que difere a tecnologia educacional das usadas nos demais setores, é o emprego usado para a educação e a prática do conhecimento. Diante do compromisso da escola com o conhecimento, cabe a ela pensar em novas formas de trabalhar esse compartilhamento de conhecimento, analisar novas práticas pedagógicas, novos comportamentos, novas maneiras de pensar e de se comunicar.
Em se tratando de tecnologia educacional, o termo traduz o emprego de recursos tecnológicos como ferramenta para melhorar a qualidade do ensino. Ao utilizar esses recursos a favor da educação há uma contribuição socioeducativa positiva na troca dos saberes. A tecnologia educacional é mais que uma "inclusão digital", é a oportunidade de conectar o estudante ao mundo atual por meio da tecnologia.

Atualmente, devido seu uso constante em áreas da Informática, Robótica e Ciências Humanas, o significado da palavra tecnologia veio tomando proporções longe do original. A globalização, o acesso democrático e a modernidade fizeram com que o termo fosse levado para outras áreas.

Para a tecnologia há que se perceber que esta não tem o mesmo significado para todos. É o uso que dela se faz que dá sentido à mesma, o que torna necessário pensá-la a partir daqueles que são entendidos, no pensamento hegemônico, apenas como seus consumidores (ALLAN, 2015, p.118).

Porém Belloni (2009) aponta que essas tecnologias são mais do que meras ferramentas a serviço do ser humano. Ao interferirem nos modos de perceber o mundo, de se expressar sobre ele e de transformá-lo, estas técnicas modificam o próprio ser humano em direções desconhecidas e talvez perigosas para a humanidade.

Esse ponto de vista também é compartilhado por Freire (1993) ao mencionar que a tecnologia não é boa nem má, não é uma pessoa para ser assim classificada. Para esse autor, a questão que devemos nos fazer é "a serviço de quem a tecnologia está?" Com base nisso, faz-se necessário refletir sobre algumas particularidades aliadas ao conceito de tecnologia tais como: que tipo de cidadão está sendo formado neste mundo tecnológico?

Ser professor, segundo Freire (1998, p. 86), implica em um compromisso constante com as práticas sociais. Desta forma,

a educação constitui-se em um ato coletivo, solidário, uma troca de 
experiências, em que cada envolvido discute suas ideias e concepções. A dialogicidade constitui-se no princípio fundamental da relação entre educador e educando. $\mathrm{O}$ que importa é que os professores e os alunos se assumam epistemologicamente curiosos (FREIRE, 1998, p. 96).

A curiosidade leva a busca por novos conhecimentos, alinhado a isso, o acesso à informação está cada vez mais veloz e dinâmico, pois, segundo Castells (2005) somos uma "sociedade em rede". Uma sociedade "onde as diferentes culturas se manifestam e operam de forma diferenciada, com intensas interações transformadoras, da rede e da própria cultura" (BONILLA; PRETTO, 2015, p. 501).

Mas será que a escola tem caminhado na mesma velocidade pela busca por conhecimento? Ou será que o que continuamos a encontrar nas salas de aula é aquele mesmo modelo antigo: grandes grupos de alunos, no mesmo local, estudando a mesma coisa simultaneamente e usando papel, lápis e um grande caderno como ferramentas e um professor ao lado da lousa com um giz na mão?

Uma escola mais contemporânea precisa envolver o ensino-aprendizagem em parceira com professores e alunos. Allan (2015) cita essa parceria como sendo: professores como agentes de mudança, e estudantes construindo seu próprio aprendizado sob a orientação dos seus professores.

Essa necessidade de ter uma escola contemporânea e refazer as metodologias de ensino surge, não apenas pelo fato da globalização, do avanço das tecnologias digitais e da utilização das TIC em sala de aula, mas também porque hoje os alunos estão predispostos a aprender de forma diferente.

O professor precisa estar pronto para lidar com os alunos conectados e informados e, muito mais que mestres, precisam ser mentores capazes de facilitar o aprendizado e ajudá-los a resolver problemas cotidianos. A participação do professor é crucial nesse processo. Não podemos imaginar que os objetos digitais de aprendizagem, por serem recursos educacionais mais sofisticados, podem por si só dar conta do

ensino. Assim,

na ação do professor na
sala de aula e no uso que
ele faz dos suportes
tecnológicos que se
encontram à disposição,
são novamente definidas
as relações entre o
conhecimento a ser
ensinado, o poder do
professor e a forma de
exploração das tecnologias
disponíveis para garantir
melhor aprendizagem
pelos alunos (KENSKI.
2012. p. 19).

Porém, muitas escolas resistem à adesão de novas tecnologias no ambiente escolar, seja, por medo de que os alunos se dispersem ou acessem materiais impróprios, ou de que não prestem atenção no conteúdo da sala de aula. Essas preocupações são pertinentes na atualidade, mas podem ser superadas com um bom planejamento de aulas e definições claras dos objetivos e regras junto com os alunos.

Cabe ao professor encontrar a melhor forma de incorporar esses novos adereços tecnológicos na sala de aula. Ou seja, deixar de lado a velha lousa de giz, o caderno pesado, o atlas, as enciclopédias e as grandes apostilas para junto com o aluno ajudá-lo a realizar a busca pelo conhecimento através dos novos recursos. Kenski (2012, p. 44) em seu estudo aborda que "a maioria das tecnologias é utilizada como auxiliar no processo educativo. [...] Elas estão presentes em todos os momentos do processo pedagógico, desde o planejamento das disciplinas, a elaboração de uma proposta curricular".

Contudo sem que os professores saibam como utilizar esses novos recursos, qualquer investimento perde o sentido. Neste contexto, "sem orientação, os professores frequentemente utilizam a tecnologia para 'fazer coisas velhas de formas novas', em vez de transformar a prática pedagógica" (ALLAN, 2015, p. 86).

Os professores precisam se reinventar, sem isso, a sociedade corre o risco de contar com uma geração de professores desatualizados que não vai saber o que fazer para propiciar boas oportunidades de aprendizagem aos seus alunos que contam com tantas informações e tecnologias à disposição.

Na educação da era conectada, não há mais espaço para uma modelo baseado em 
apostilas, enciclopédias, livros produzidos em massa e com conteúdo defasado. No mundo da interatividade, da mobilidade, do digital e da vida conectada, é preciso também reinventar o material didático. Com essa transformação por conta da tecnologia, o velho material didático está fadado à aposentadoria. Um tablet, um notebook ou até mesmo um celular carrega todos os livros e cadernos e permite interatividade e atualização, o que não ocorre com a versão impressa.

Uma das estratégias de aprendizagem para o mundo contemporâneo é o comportamento do educador. Ele precisa aprender a aprender, inclusive junto com os alunos, e aprender as funcionalidades dos recursos tecnológicos básicos. Porém, não deve se preocupar caso os estudantes saibam mais que ele. Há sempre uma troca saudável entre professor e aluno e a partir disso surge uma experiência enriquecedora para todas as partes, inclusive a escola.

A verdade é que todo método, tática, estratégia que promova o envolvimento, interação e participação do aluno no processo de ensino e aprendizagem contribui para a formação de um novo aluno com uma visão global da realidade e que é preparado para lidar com problemas e situações reais no seu dia a dia.

\section{MÉTODOS}

Segundo Gil (2002, p. 44), "uma pesquisa bibliográfica é desenvolvida com base em material já elaborado, constituído principalmente de livros e artigos científicos". Assim, para este trabalho, inicialmente, fez-se uma pesquisa bibliográfica sobre como as TIC são usadas por docentes de escolas de nível técnico, de forma a embasar a montagem de um questionário posteriormente aplicado a alguns docentes.

De acordo com Manfroi (2006, p.15), "o pesquisador busca conseguir, através da conversação, dados que possam ser utilizados em análise qualitativa, ou seja, os aspectos considerados mais relevantes de um problema de pesquisa". Neste contexto, uma "entrevista, pode ser entendida como a técnica que envolve duas pessoas numa situação [...] em que uma delas formula questões e a outra responde" (GIL, 2002, p. 114).

Para esse estudo a entrevista semiestruturada ou semiaberta foi escolhida para colher dados entre os professores entrevistados. Conforme Duarte e Barros (2006) explicam a lista de questões aplicadas em uma entrevista semiaberta tem origem no problema de pesquisa e busca tratar da amplitude do tema, apresentando cada pergunta da forma mais aberta possível. Uma entrevista semiaberta geralmente tem entre quatro ou sete questões, tratadas individualmente como perguntas abertas.

Nesse tipo de entrevista, o entrevistador faz a primeira pergunta e explora ao máximo cada resposta até esgotar a questão. Somente assim, passa para a segunda pergunta. Segundo Duarte e Barros (2006) cada questão é aprofundada a partir das respostas do entrevistado, como um funil, no qual perguntas gerais vão dando origem a específicas. A entrevista é conduzida, em grande medida, pelo entrevistado, valorizando seu conhecimento, mas ajustada ao roteiro do pesquisador.

A entrevista pode ter um roteiro, mas é natural ser conduzida de formas diferentes e acabar de forma surpreendente. Para Alves e Silva (1992) esse formato exige uma formulação flexível das questões, cuja sequência e minuciosidade ficarão por conta do discurso dos sujeitos e da dinâmica que flui naturalmente no momento em que o entrevistador e entrevistado se defrontam e partilham uma conversa permeada de perguntas abertas.

Duarte e Barros (2006) apontam as vantagens desse modelo de entrevista, e uma delas é permitir criar uma estrutura para comparação de respostas e articulações de resultados, auxiliando na sistematização das informações fornecidas por diferentes informantes.

Nesse estudo foram feitas entrevistas com dois docentes de uma escola de nível técnico. Um com maior experiência na atividade docente e outro com menor. Nestas entrevistas usou-se um questionário elaborado previamente.

A entrevista foi utilizada para identificar as diferentes formas de interação entre docentes e as TIC, primariamente entre o docente que utiliza as TIC de uma maneira nativa e o docente que as veem como um mundo ainda a ser descoberto. Criando, assim, um contraponto de opiniões.

Os sujeitos entrevistados foram escolhidos por lecionarem em um Curso Técnico de Administração, no interior do estado de São Paulo. Os entrevistados, além de possuírem tempo diferente na docência, também são de faixas etárias distintas. Para não usar os reais 
nomes dos sujeitos, eles serão identificados como: Professor 1 e Professor 2. O Professor 1 leciona na escola técnica há quase duas décadas e o Professor 2 leciona na escola técnica há 5 anos.

As entrevistas informais ocorreram na escola técnica onde ambos os docentes lecionam, no mês de julho do ano de 2017.

A entrevista informal com o Professor 1 teve duração de 6 minutos e 23 segundos, e a entrevista com o Professor 2 teve duração de 7 minutos e 58 segundos. Para melhor transcrição foi escolhida a gravação como meio de escuta e transmissão das perguntas e respostas.

\section{RESULTADOS}

Com base nas entrevistas realizadas com os docentes do Curso Técnico de Administração que utilizam novas tecnologias para ensinar seus alunos, os dois entrevistados responderam a quatro questões sobre o tema.

O Professor 1 relatou que possui grande dificuldade de interação com tecnologias, devido a sua idade avançada Ele cita que possui apenas conta de e-mail e que acessa a internet apenas por um dispositivo móvel que fica na sua residência, sendo que esse acesso é apenas profissional. Além disso, ele considera tecnologia apenas computadores e smartphones.

0 entrevistado relata as influências positivas que teve em sua carreira, destacando a importância da didática e da prática de alguns professores:

Eu tive excelentes
professores e hoje me
inspiro neles. Não adianta
ter grandes aparatos
tecnológicos e não
dominar o conteúdo da
sua disciplina. Lembro-me
dos recursos que meus
professores utilizam e
eram apenas: lousa e giz.
Já que deu certo dessa
maneira procuro fazer com
meus alunos (PROFESSOR
1, 2017).

O Professor 2 relatou que usa a tecnologia como sua aliada no processo de ensino aprendizagem. Ele exemplificou um trabalho que pediu aos seus alunos, onde era necessário produzir um conteúdo pela câmera do celular, fotografar, gravar, filmar, editar e compartilhar o trabalho.

Sobre os saberes resultantes da prática tecnológica se posicionou:

Com a prática docente, descobri muitas coisas. A integração dos alunos com a tecnologia através de compartilhamento tem me dado elementos muitos ricos. Descobri que existem diversas maneiras para dinamizar o aprendizado do aluno. Tem sido um desafio muito grande e difícil, porque você tem que recriar suas aulas para atingir a sala de aula. Porém esses novos métodos demostraram grande interesse, aceitação e participação dos alunos (PROFESSOR 2, 2017).

Ambos os professores citaram em suas entrevistas a real importância e urgência de cursos de capacitações envolvendo as tecnologias. Citaram também que são poucos os professores que sabem aproveitar esses recursos devido à ausência de aprendizagem sobre eles.

Um dos focos das
capacitações deveria ser a
prática docente perante as
novas tecnologias. Nós
temos muitas dificuldades.
Os alunos acabam
ensinando para nós dentro
da sala de aula
(PROFESSOR 1, 2017).

Uma pesquisa realizada em Campinas pela Unicamp entre 2009 e 2010, e apresentada por Oda (2011), aponta que apenas $27 \%$ dos docentes, pesquisados entre 27 escolas, realizaram cursos para uso didático da tecnologia. Esses dados só vêm afirmar que a maior barreira para a utilização das TIC em sala de aula é a falta de treinamento dos docentes.

O Professor 2 expõe o curso de Administração como um dos cursos que mais exigem tecnologia no seu dia a dia em sala de aula.

As tecnologias, na área da Administração e Gestão, são muito importantes porque a gente está sempre descobrindo coisas novas e a internet é um recurso para ter contato com as pesquisas de ponta no mundo. A área da 
Administração exige

softwares,

empreendedorismo,

contato online e buscas

(PROFESSOR 2, 2017).

O Professor 2 complementou, ainda, a importância de estar atualizado quanto aos novos recursos:

$$
\begin{aligned}
& \text { Eu procuro conhecer, } \\
& \text { aprender e descobrir } \\
& \text { novas tecnologias para } \\
& \text { abordar os eventos do } \\
& \text { cotidiano, para que os } \\
& \text { alunos consigam visualizar } \\
& \text { aquilo que estou falando }
\end{aligned}
$$

em aula. Além disso, eu busco vídeos, filmes, entrevistas e debates [...] enfim, tudo o que tem a ver com o conteúdo (PROFESSOR 2, 2017).

O Professor 2, aponta a importância de conhecer novas tecnologias e aplica-las em sala de aula. Um estudo realizado por Teixeira (2017), em uma escola de ensino médio integrado ao técnico, corrobora tal percepção. Nele os alunos responderam que $64 \%$ dos professores demonstram que sabem utilizar as TIC, como observamos na Figura 1.

Figura 1. Percepção dos alunos em relação ao uso de TIC pelos seus professores.

Fonte: Teixeira (2017, p. 77)

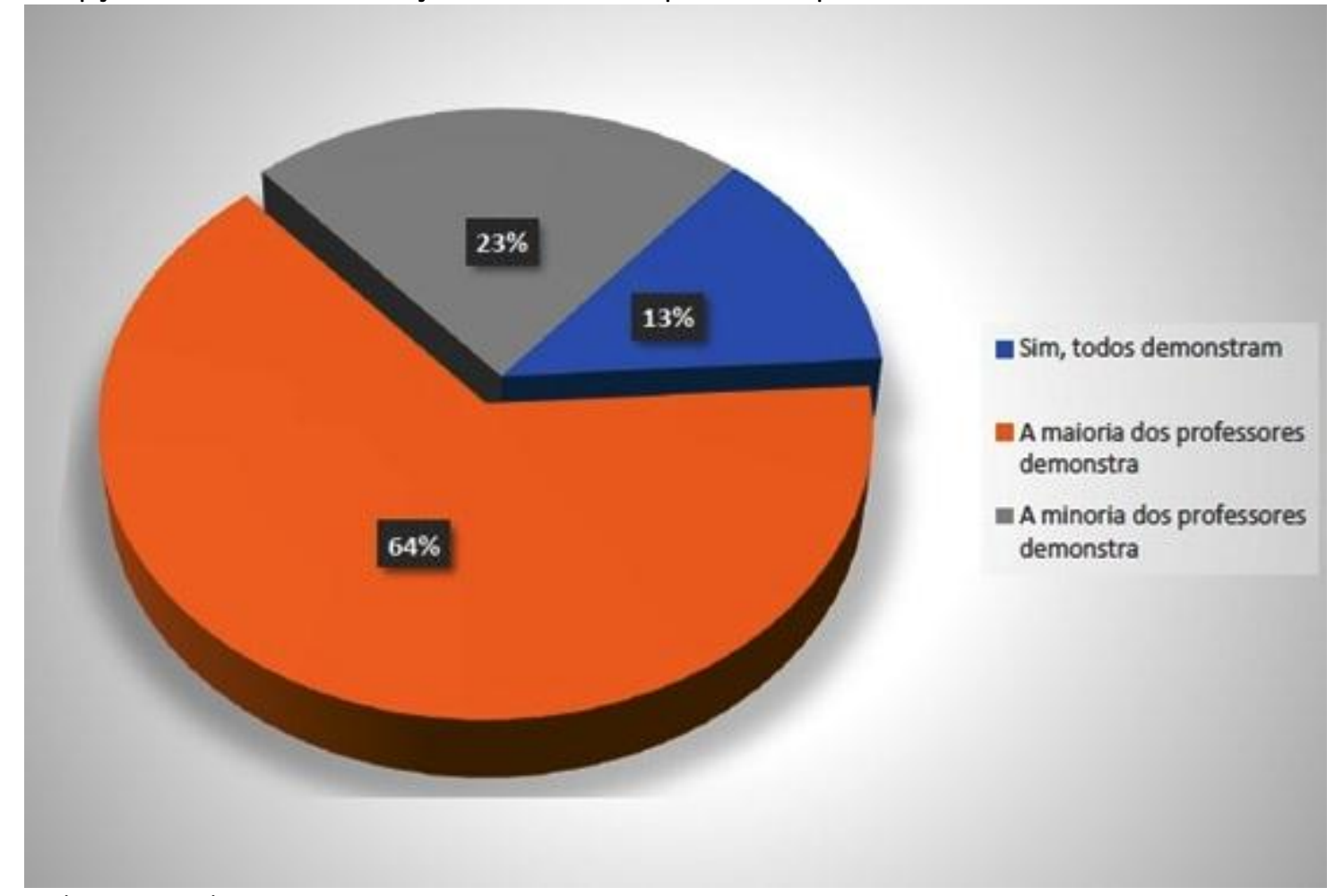

Uma grande dificuldade apontada pelo Professor 1 são os conteúdos trabalhados na prática dos laboratórios de informática dentro da escola.

Boa parte dos laboratórios não funcionam, pois, suas máquinas estão quebradas ou danificadas. Alguns até funcionam, porém estão ultrapassados. Os alunos aprendem softwares que não condizem com a atualidade e nem com a realidade. Eu acredito que mais de $50 \%$ dos meus

$$
\begin{aligned}
& \text { alunos não entendem } \\
& \text { nada de informática } \\
& \text { (PROFESSOR 1, 2017). }
\end{aligned}
$$

Outros fatores que podem dificultar a implementação das novas tecnologias e que foram citados pelos dois docentes: falta de conhecimento prévio das funcionalidades dos materiais tecnológicos que serão usados pelos docentes, à ausência do professor no processo de desenvolvimento dessas novas práticas educativas e, principalmente, a infraestrutura.

Teixeira (2017) observa uma baixa utilização das TIC pelos professores, como visto 
na Figura 2. Tal taxa de utilização pode estar ligada às dificuldades narradas pelos dois entrevistados.

Figura 2. Frequência de utilização das TIC por professores.

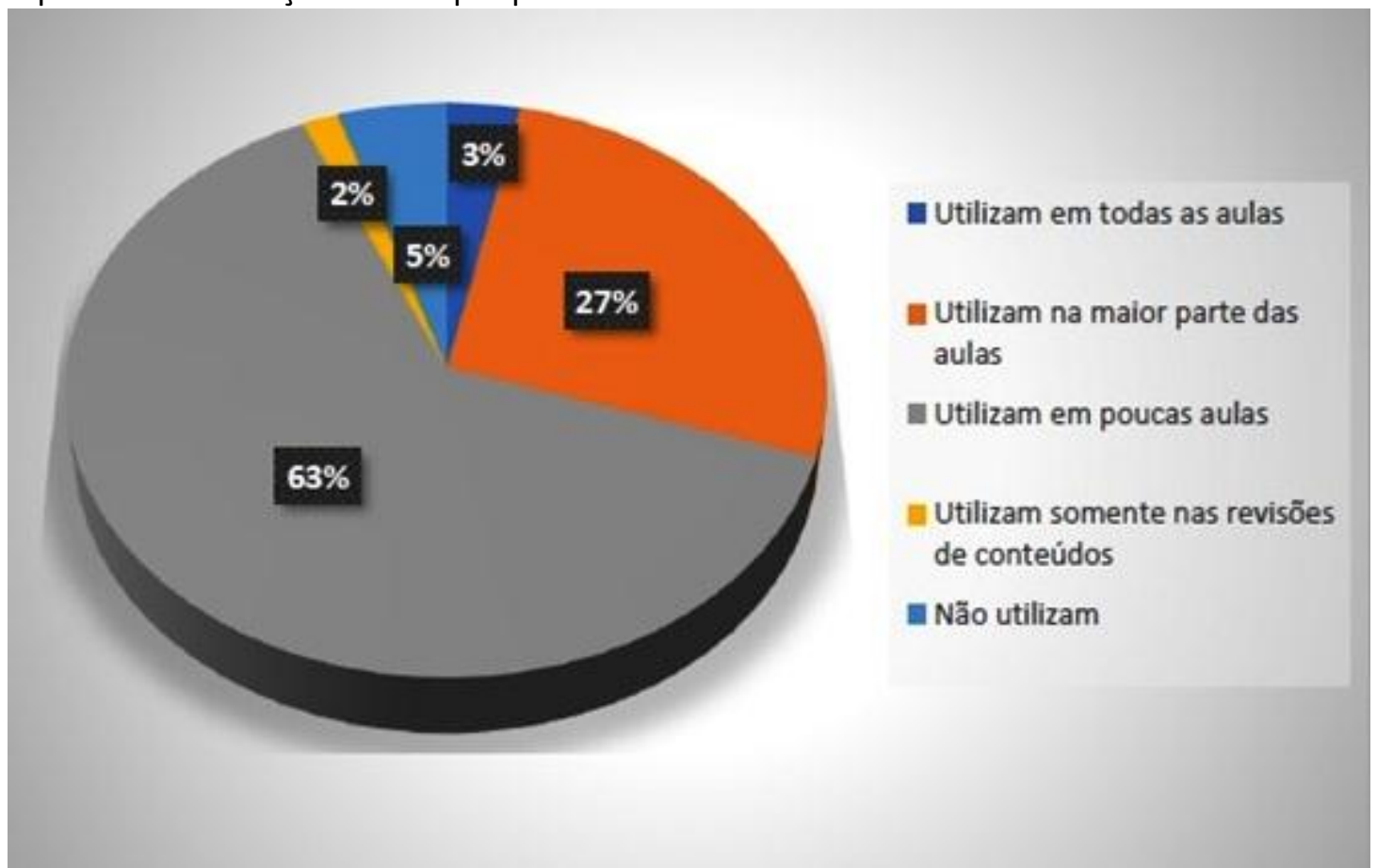

Fonte: Teixeira (2017, p. 76)

A infraestrutura foi mencionada mais de sete vezes no discurso dos professores como sendo um dificultador para a utilização das TIC no ambiente escolar. Corroborando que a falta de infraestrutura é um dos motivos pela não adoção em sua totalidade nas escolas, Oda (2011), em seu artigo, afirma que $73 \%$ dos entrevistados para a pesquisa naquela localidade afirmaram que a infraestrutura é um dos motivos pela não utilização das TIC em sala de sala.

Neste contexto, uma pesquisa, realizada pelo Cetic.br, apresenta dados relevantes sobre a estrutura nas escolas. Assim,

$$
\begin{aligned}
& \text { as escolas relataram } \\
& \text { dificuldades no número e } \\
& \text { na qualidade dos } \\
& \text { equipamentos disponíveis, } \\
& \text { mencionando também } \\
& \text { problemas recorrentes na } \\
& \text { sua manutenção. Nas } \\
& \text { escolas participantes, a } \\
& \text { relação do número de } \\
& \text { alunos por equipamento } \\
& \text { (desktop, notebook e } \\
& \text { tablet) em funcionamento } \\
& \text { disponível para uso } \\
& \text { pedagógico varia de dez a } \\
& 64 \text { alunos para cada } \\
& \text { equipamento. Apenas } 31 \% \\
& \text { reportaram possuir até } 15
\end{aligned}
$$

\begin{abstract}
alunos por equipamento na escola. Além disso, em $75 \%$ das escolas, os equipamentos estão localizados nos laboratórios de informática, com acesso limitado e esporádico. Em $21 \%$, os computadores são utilizados apenas para fins administrativos. Apenas $3,2 \%$ das escolas contam com computadores para uso pedagógico dentro de salas de aula (COMITÊ GESTOR DA INTERNET NO BRASIL, 2016, p. 37).
\end{abstract}

\section{DISCUSSÃO}

Através desse trabalho conclui-se que as novas tecnologias usadas com a finalidade educacional e pedagógica ampliam as possibilidades de o professor ensinar e do aluno aprender.

Quando usada com critério e conhecimento, a tecnologia pode contribuir para a aprendizagem e a melhoria no ensino. Entretanto, o professor precisa buscar conhecer e estar consciente de que ao adotar esse novo recurso na área educacional terá reflexos na sua 
prática docente e nos processos pela busca de conhecimento.

Teixeira (2017, p. 99), em seu estudo, apresenta opinião similar quando menciona a "necessidade de facilitar o acesso dos docentes a instrumentos que possam orientar suas práticas voltadas ao uso das tecnologias em sala de aula".

Através das entrevistas informais realizadas com dois professores de escola técnica do Curso de Administração verificou-se, a importância do uso das novas tecnologias, a ausência de capacitações para os docentes, as falhas na infraestrutura, o aumento do interesse do aluno, como também o aumento da motivação e participação.

Um dado importante detectado nessas entrevistas foi a predisposição dos dois professores em lidar e aprender com as novas tecnologias na prática cotidiana da sala de aula.

Outra informação importante descoberta durante a análise foi a distinção entre utilizar as tecnologias como instrumento facilitador da aprendizagem nos processos de ensino e o simples ato de substituir as "velhas" tecnologias como giz, livro e lousa, pelas novas tecnologias sem ao menos mudar o discurso, metodologia, postura e as relações didáticas.

Outra constatação é a existência de duas posturas distintas por parte dos docentes entrevistados em relação ao computador. Para o Professor 1, o computador é algo muito distante da realidade dos alunos da sala de aula, distante também da maneira de ensinar e de aprender. Já - Professor 2 demonstra a importância da inserção da tecnologia na sala de aula independente da realidade que o aluno vive fora da escola, pois esses alunos ganham conhecimento para o mercado de trabalho.

\section{REFERÊNCIAS}

ALLAN, L. Escola.com: Como as novas Tecnologias estão transformando a educação na prática. 1. ed. Barueri: Figurati, 2015.

ALVES, Z.; SILVA, M. H. Análise qualitativa de dados de uma entrevista: proposta. Paidéia. Ribeirão Preto, v2, fev./jul. 1992. Disponível em $<$ http://www.scielo.br/scielo.php?script=sci_artte xt\&pid=S0103-863X1992000200007>. Acesso em: 10 nov. 2018.

BELLONI, M. L. O que é mídia-educação. 3. ed. Campinas: Autores Associados, 2009.
BONILLA, M. H. S.; PRETTO, N. de L. Política educativa e cultura digital: entre práticas escolares e práticas sociais. Perspectiva, Florianópolis, v. 33, n. 2, p. 499-521, mai./ago. $2015 . \quad$ Disponível em: $<$ https://periodicos.ufsc.br/index.php/perspectiv a/article/view/2175-

795X.2015v33n2p499/31292>. Acesso em: 17 nov. 2018.

CASTELLS, M. A sociedade em rede. São Paulo: Paz e Terra, 2005.

COMITÊ GESTOR DA INTERNET NO BRASIL CGI.BR. Pesquisa Sobre o Uso das tecnologias de Informação e Comunicação nas Escolas Brasileiras. 2016. Disponível em <https://www.cetic.br/media/docs/publicacoes/2 /TIC_EDU_2016_LivroEletronico.pdf >. Acesso em: 16 nov. 2018

DUARTE, J.; BARROS, A. Métodos e técnicas de pesquisa em comunicação. 2. ed. São Paulo: Atlas, 2006.

FERNANDES, M. E. Memória Camponesa. In: REUNIÃO ANUAL DE PSICOLOGIA, 21, 1991, Ribeirão Preto. Anais... Ribeirão Preto : SPRP, 1991. p. 20. No prelo.

FREIRE, P. Pedagogia da Esperança: um reencontro com a pedagogia do oprimido. 2. ed. Rio de Janeiro: Paz e Terra, 1993.

FREIRE, P. Pedagogia da autonomia. 7. ed. Rio de Janeiro: Paz e Terra, 1998.

GIL, A. C. Como elaborar projetos de pesquisa. 4. ed. São Paulo: Editora Atlas S.A, 2002.

KENSKI, V. M. Educação e tecnologias: o novo ritmo da informação. 8 ed. Campinas: Papirus, 2012.

MANFROI, J. Curso de Pós-Graduação Lato Sensu a Distância: disciplina de Métodos e Técnicas de Pesquisa. Campo Grande: UCDB/EAD, 2006. Disponível em: <https://virtual.ucdb.br/TUTORIAL_MOODLE/file s/Metodos_e_Tecnicas_de_Pesquis-23-08-2006EADUCDB.pdf>. Acesso em 07 ago. 2017.

ODA, F. Professores são inseguros para usar a tecnologia. Estadão. São Paulo, 11 abr. 2011. 
Caderno Educação. Disponível em: <http://educacao.estadao.com.br/noticias/geral, $\mathrm{p}$ rofessores-sao-inseguros-para-usar-

tecnologia,704780>. Acesso em 26 jul. 2017.

PACIEVITCH, T. Tecnologia da Informação e

Comunicação. 2018. Disponível em: <https://www.infoescola.com/informatica/tecnol ogia-da-informacao-ecomunicacao/https://www.infoescola.com/infor matica/tecnologia-da-informacao-ecomunicacao/>. Acesso em 15 mar. 2018.

PROFESSOR 1. Entrevista I. Entrevistadores: Ana Cristina Cardoso Coimbra, Fabiana Helena Zen Gorayeb. Ribeirão Preto/SP, jul. 2017. Entrevista concedida para fins de pesquisa.

PROFESSOR 2. Entrevista I. Entrevistadores: Ana Cristina Cardoso Coimbra, Fabiana Helena Zen Gorayeb. Ribeirão Preto/SP, jul. 2017. Entrevista concedida para fins de pesquisa.

TEIXEIRA, A. N. O uso das tecnologias da informação e comunicação como facilitador no processo de aprendizagem no ensino técnico integrado ao médio. 2017. Dissertação de Mestrado (PPGMiT, da Faculdade de Arquitetura, Artes e Comunicação - FAAC) Universidade Estadual Paulista "Júlio de Mesquita Filho UNESP - Bauru, 2017. Disponível em: <https://repositorio.unesp.br/bitstream/handle/1 1449/150754/teixeira_an_me_bauru.pdf?sequenc e=3\&isAllowed $=y>$ Acesso em 18 ago.2017

Recebido para avaliação: 27/05/2018

Revisado em: 01/11/2018

Aceite Final: 03/11/2018 